\title{
Static lung volumes in healthy subjects assessed by helium dilution during occlusion of one mainstem bronchus
}

B Johansen, Ø Bjørtuft, J Boe

\begin{abstract}
Background-Single lung function is usually assessed by radioisotopes or, more rarely, by bronchospirometry in which a double lumen catheter is used to separate ventilation of the two lungs. The latter is more precise but less comfortable. An alternative bronchoscopic method is described for determining the volume of a single lung.
\end{abstract}

Methods-One mainstem bronchus was temporarily occluded with an inflatable balloon during fibreoptic bronchoscopy in 12 healthy volunteers aged 18-29 years. The functional residual capacities (FRC) of the right, left, and both lungs were measured in duplicate by closed circuit helium dilution. Supplementary vital capacity (VC) manoeuvres permitted calculation of single lung capacities (TLC) and residual volumes (RV).

Results-The standard deviation of a single determination of capacities of the right, left, and both lungs were: TLC, 80 , 96, and $308 \mathrm{ml}$; VC, 56, 139, $171 \mathrm{ml}$; FRC, 131,74 , and $287 \mathrm{ml}$, RV, 112, 185, and 303 $\mathrm{ml}$, respectively. The sum of the right and left unilateral TLC was not different from bilateral TLC $(6 \cdot 12 v 5.951)$ and the sum of the unilateral FRC was not different from the bilateral FRC $(2.60 v 2.781)$. The sum of the unilateral VC was lower than bilateral VC $(4.52 v 4.801)$, that of the unilateral RV was higher than bilateral RV (1.60 $v 1 \cdot 16$ 1). For all subdivisions of lung volume, the right lung was larger than the left. The most common complaint was substernal discomfort during complete exhalation. Oxygen saturation rarely fell below $90 \%$.

Conclusions-Temporary occlusion of a mainstem bronchus in normal subjects is safe, relatively simple, and allows fairly precise and accurate measurements of unilateral static lung volumes. Occlusion at TLC, however, probably prevents proper emptying of the non-occluded lung.

(Thorax 1993;48:381-384)

Few tests are available to measure the function of a single lung. Isotope scans provide the fractional distribution of perfusion and ventilation to each lung and are used in the preoperative assessment of patients with bronchial carcinomas ${ }^{1}$ and in the follow up after single lung transplantation. ${ }^{2}$ Bronchospirometry, in which an intubated double lumen catheter separates flow in the two lungs, has previously been used for preoperative assessment. ${ }^{3}$ Distribution of ventilation, lung volumes, and other common indices of single lung function can also be assessed by this technique.

The procedure described here is a more comfortable form of bronchospirometry. During temporary occlusion of one mainstem bronchus by an inflatable balloon, standard pulmonary function tests can be applied to the other lung. The balloon is positioned during fibreoptic bronchoscopy after topical anaesthesia. We have evaluated the method in healthy subjects and measured their static lung volumes separately for the right and left lungs.

\section{Methods}

SUBJECTS

Twelve healthy volunteers (eight men and four women) aged 18-29 years, smokers and non-smokers, participated in the study. They were recruited from staff members, relatives, and medical students and had no history of respiratory or cardiac disease. None had had any respiratory symptoms and their ventilatory lung function was within normal limits as determined by dynamic spirometry on the day of the investigation. ${ }^{4}$ Two additional subjects were excluded; one man who fainted during bronchoscopy but before the balloon was inflated, and a woman who cooperated well but during the measurements a leak was discovered in a spirometer hose.

\section{TECHNICAL EQUIPMENT}

Fogarty venous thrombectomy catheters (size $8 / 10$ French), $80 \mathrm{~cm}$ in length, were used with a maximum diameter of $19 \mathrm{~mm}$ with the balloon inflated and a balloon capacity of 4 ml (American Edwards Laboratories, Santa Ana, California, USA). The catheter was advanced into the airways under guidance of an Olympus paediatric fibreoptic bronchoscope (BF 3C10) with an outer diameter of $3.9 \mathrm{~mm}$.

\section{STUDY DESIGN}

Lung volumes

Static lung volumes were measured under 
BTPS conditions by the closed circuit helium dilution method with a Gould automated system 2400 (Sensormedics BV, Bilthoven, The Netherlands). Inhalation of the gas mixture started at the subjects' functional residual capacity (FRC). The equilibrium criterion was set to $0.05 \%$. Oxygen was delivered automatically. The vital capacity (VC) manoeuvres were performed near the end of equilibration. From the FRC and VC recordings, values for total lung capacity (TLC) and residual volume (RV) were derived. When unilateral values for TLC, FRC, and RV from one lung were added to those of the other, $85 \mathrm{ml}$ was subtracted from the total to correct for the volume of the upper airway, trachea, and mainstem bronchi that had been measured twice. ${ }^{5}$ Reference values for TLC were those of the European Community for Coal and Steel. ${ }^{4}$

\section{Insertion procedure}

After premedication with atropine, diazepam and hydrocodone, the seated subjects inhaled $5 \mathrm{ml}$ of $2 \%$ nebulised oxybuprocaine via a nasal mask. The nostrils and the posterior wall of the pharynx were also sprayed with lignocaine aerosol. The bronchoscope, coated with $2 \%$ lignocaine gel, was inserted into the left nostril and advanced until the glottis became visible. The slightly bent catheter with its stylet inside was advanced blindly through the other nostril until its tip became visible. By twisting the proximal part of the catheter, sliding the stylet back and forth, and changing the position of the subject's head, it was relatively easy to steer the catheter, followed by the bronchoscope, between the vocal cords and into the trachea. The stylet was then removed and the tip of the catheter placed in one mainstem bronchus. Extra topical anaesthesia was usually needed, both in the trachea and in the mainstem bronchi, to avoid coughing.

\section{Balloon position check}

The subjects were asked to inhale as deeply as possible and then to hold their breath. Under visual control the balloon was inflated rapidly with saline until it occluded the airway completely. On the right side the balloon was inflated at the level of the orifice to the upper lobe, and on the left as far down the mainstem bronchus as possible. The subjects then breathed normally for three or four breaths while the position of the balloon was checked before it was deflated. The inflation and deflation procedure was repeated several times to adjust the position of the balloon and the necessary volume of fluid. The catheter was then fixed to the nostril by tape and a nose clip, the bronchoscope removed and the subjects were placed in front of the spirometer still seated.

\section{Test procedure}

The subjects had been made familiar with the gas dilution method before bronchoscopy and were told to fill the lungs slowly and hold their breath. The predetermined volume of saline was injected to inflate the balloon and the subjects were told to breathe quietly while being connected to the mouthpiece of the spirometer. At the end of a normal expiration they were connected to a mixture containing helium and continued tidal breathing until the equilibrium criterion was reached. During equilibration, one or two slow VC manoeuvres were performed. The balloon was deflated immediately after each test. Usually four unilateral and two bilateral measurements were made in each subject: two with the balloon inflated in the right lung, two when it was blocking the left lung, and two with the balloon deflated. The subjects had a repeat bronchoscopy when the catheter was moved from one mainstem bronchus to the other. When the balloon was in the short right mainstem bronchus its position was often checked between duplicate measurements.

\section{Safety}

During the insertion and measurement procedure the heart rate and oxygen saturation were recorded continuously by a Minolta Pulsox-7 oxygen saturation monitor. Whenever the balloon was inflated, one technician held the syringe and was ready to deflate it within seconds if necessary. The subjects were informed about possible unpleasant feelings when the balloon was inflated and were told to tap their fingers if they wanted it deflated during the test.

\section{Randomisation and statistics}

The subjects were examined in the order they had been recruited. The order of measurement of the right, left, or both lungs was randomised for each subject according to a complete block design. SPSS (Statistical Package for the Social Sciences) was used for the data entry and analysis. Reproducibility was expressed as the standard deviation of a single determination (standard deviation of the difference between duplicates divided by the square root of two). Comparisons between mean values for each variable from each lung and from both lungs were made by the two tailed paired $t$ test.

\section{Ethical considerations}

Each subject was informed carefully about the purpose and content of the study, both verbally and in writing. All gave written informed consent to participate. The study was approved by the Regional Health Area Ethical Committee.

\section{Results}

PRACTICAL

The bronchoscopic procedure, including positioning of the balloon, lasted 9-21 minutes. The whole procedure, including necessary repeat bronchoscopies and the six measurements lasted an average of $62 \mathrm{~min}$ utes (range 51-74). In one man, $196 \mathrm{~cm}$ tall, measurements were done only once on both sides. In two other men we were able to block the right mainstem bronchus only once. It 
Table 1 Group mean and standard deviation, standard deviation of a single determination and coefficient of variation of unilateral and bilateral static lung volumes measured in duplicate in nine healthy volunteers

\begin{tabular}{|c|c|c|c|c|c|}
\hline Variable & $n$ & $\begin{array}{l}\text { Mean } \\
\text { (l) }\end{array}$ & $\begin{array}{l}S D \\
\text { (l) }\end{array}$ & $\begin{array}{l}\text { SD of a single } \\
\text { determination } \\
\text { (l) }\end{array}$ & $\begin{array}{l}\text { Coefficient of } \\
\text { variation } \\
(\%)\end{array}$ \\
\hline TLC, right & 11 & $3 \cdot 37$ & 0.532 & 0.080 & $2 \cdot 4$ \\
\hline TLC, left & 9 & 2.94 & 0.359 & 0.096 & $3 \cdot 3$ \\
\hline TLC, both & 12 & $6 \cdot 24$ & 0.963 & 0.308 & 4.9 \\
\hline FRC, right & 11 & 1.53 & 0.393 & $0 \cdot 131$ & $8 \cdot 6$ \\
\hline FRC, left & 9 & $1 \cdot 28$ & $0 \cdot 245$ & 0.074 & $5 \cdot 6$ \\
\hline FRC, both & 12 & 3.05 & 0.465 & $0 \cdot 287$ & $9 \cdot 4$ \\
\hline VC, right & 11 & $2 \cdot 41$ & 0.442 & 0.056 & $2 \cdot 3$ \\
\hline VC, left & 9 & $2 \cdot 17$ & 0.364 & 0.139 & $6 \cdot 4$ \\
\hline VC, both & 12 & 4.93 & 0.919 & $0 \cdot 171$ & 3.5 \\
\hline$R V$, right & 11 & 0.96 & 0.359 & $0 \cdot 112$ & $11 \cdot 7$ \\
\hline RV, left & 9 & $0 \cdot 77$ & $0 \cdot 287$ & $0 \cdot 185$ & $24 \cdot 0$ \\
\hline RV, both & 12 & $1 \cdot 31$ & 0.408 & 0.303 & $23 \cdot 1$ \\
\hline
\end{tabular}

TLC-total lung capacity; FRC—functional residual capacity; VC—vital capacity; RVresidual volume.

was never necessary to interrupt the measurements because of dyspnoea, cough, pain, or fatigue. The oxygen saturation usually remained above $90 \%$ but on three occasions (of 44 in total) it fell rather abruptly to $86 \%$ at the end of the occlusion period. The most common complaint from the subjects, apart from those related to bronchoscopy, was an unpleasant, somewhat painful sensation at the sternum on exhaling to residual volume.

\section{PRECISION}

There was no systematic difference between duplicate values. Table 1 shows that the standard deviation of a single determination was smaller for unilateral than for bilateral variables, smaller for TLC than for RV, and smaller for right than for left lung variables. When reproducibility was expressed as coefficient of variation, unilateral variables varied no more than bilateral ones.

Table 2 Comparison of mean (SE) sums of right and left unilateral static lung volumes (corrected for volume measured twice) and bilateral lung volumes in nine healthy volunteers

\begin{tabular}{lllll}
\hline & $\begin{array}{l}\text { Sum of } \\
\text { unilateral } \\
\text { volumes } \\
\text { (l) }\end{array}$ & $\begin{array}{l}\text { Bilateral } \\
\text { volume } \\
\text { (l) }\end{array}$ & $S E_{d}$ & $p$ \\
\hline TLC & $6 \cdot 12(0.28)$ & $5.95(0.32)$ & 0.076 & 0.056 \\
VC & $4.52(0.27)$ & $4 \cdot 80(0.31)$ & 0.118 & 0.050 \\
FRC & $2 \cdot 60(0 \cdot 15)$ & $2 \cdot 78(0 \cdot 16)$ & 0.083 & 0.065 \\
RV & $1.60(0 \cdot 18)$ & $1.16(0.14)$ & 0.088 & 0.001 \\
\hline
\end{tabular}

$\mathrm{SE}_{\mathrm{d}}-$ standard error of difference between means. For definition of other abbreviations see table 1 .

Table 3 Comparison of mean (SE) left and right unilateral static lung volumes in nine healthy volunteers

\begin{tabular}{lllll}
\hline Variable & $\begin{array}{l}\text { Right lung } \\
\text { () }\end{array}$ & $\begin{array}{l}\text { Left lung } \\
\text { (l) }\end{array}$ & $S E_{d}$ & $p$ \\
\hline TLC & $3.27(0.16)$ & $2.94(0.12)$ & 0.068 & 0.001 \\
VC & $2.36(0.16)$ & $2.17(0.12)$ & 0.066 & 0.022 \\
FRC & $1.40(0.08)$ & $1.28(0.08)$ & 0.048 & 0.034 \\
RV & $0.91(0.09)$ & $0.77(0.09)$ & 0.059 & 0.043 \\
\hline
\end{tabular}

For definition of abbreviations see tables 1 and 2 .

\section{ACCURACY}

Table 2 shows the sum of right and left unilateral VC and the corrected sum of right and left lung TLC, FRC, and RV compared with the same variables when both lungs were measured simultaneously. There was no statistical difference between the sum of unilateral TLC and the bilateral value, nor between the sum of unilateral FRC and bilateral FRC. The combined VC from each lung was smaller than the bilaterally measured volume. The sum of unilateral RV was significantly larger than that for both lungs. Bilateral TLC varied between 80 and $110 \%$ (mean $92 \%$ ) of the predicted values. ${ }^{4}$ The results in table 3 show that for all subdivisions of volume, the right lung was significantly larger than the left.

\section{Discussion}

We have presented an alternative way of measuring unilateral lung function which gives reproducible and accurate results for TLC and FRC. The RV of a single lung was overestimated and the VC was consequently lower than conventional measurements. A possible explanation for this is given later.

In the first attempt, 60 years ago, to measure split lung function, a double lumen bronchoscope separated ventilation between the two lungs. ${ }^{6}$ Subsequent modifications to this technique, designated bronchospirometry, included the use of two spirometers ${ }^{7}$ and sequential examinations of each lung with only one bronchoscope. ${ }^{8}$ When flexible single or double lumen catheters became available, in particular that proposed by Carlens, ${ }^{9}$ the procedure was better tolerated by patients and results were more reliable. Values for subdivisions of lung volumes in healthy adults were obtained by Svanberg. ${ }^{10}$ Bronchospirometry has primarily been used to quantify ventilation and gas exchange in each lung as a preoperative procedure. ${ }^{311}$ Since isotope methods have become available, however, bronchospirometry has seldom been performed.

The most important disadvantage of our method is the unstable position of the inflated balloon in the short right mainstem bronchus. Stability is increased if inward pressure is exerted on the catheter after the balloon has been inflated.

We chose to occlude the bronchus at TLC because it is easier to know when someone is at an extreme volume than at FRC, and because it became obvious that most subjects found it more unpleasant to have the balloon inflated at RV than at TLC. Occlusion at TLC is preferable from the viewpoint of gas exchange, particularly in tests that last for several minutes. At maximal inspiration there is a large reservoir of inspired air in the lung to be occluded. In addition, the regional distribution of blood flow matches ventilation better at TLC than at RV. ${ }^{12}$ Both factors, together with a probable shift of perfusion towards the non-occluded lung, ${ }^{13}$ can explain why a satisfactory oxygen saturation is maintained even during measurements that last for 
more than three minutes.

The fact that the balloon was inflated at TLC is probably the reason why this was the most, and RV was the least, reproducible unilateral static volume. The combination of a "braking" effect of an expanded lung on its neighbour during expiration and the subjective discomfort mentioned earlier may explain why RV varied more than TLC. The braking effect may also explain the higher than expected unilateral RV and the lower VC. If this is true, the native emphysematous lung in single lung transplanted patients might have a similar effect on the transplanted lung. The larger measurement error for VC, and hence $R V$, of the left lung could be due to an unwanted bias of the investigators. When the subjects exhaled to RV with the balloon in the right mainstem bronchus, the concern that it could be expelled into the trachea may have influenced our instructions during the VC manoeuvre.

The difference in size between the right and left lung found at necropsy ${ }^{14}$ and in physiological studies ${ }^{10} 15$ was convincingly confirmed by our results. The finding that the size difference pertains to all subdivisions of lung volume was in agreement with a previous report. ${ }^{10}$

This method is accurate, but only if compared with measurements on both lungs under the same conditions-for example, premedication, topical anaesthesia, and bronchoscopy. Its strength, however, is its accuracy in relative terms. The values of unilateral volumes from one lung could be subtracted from those obtained from both lungs measured under the same conditions. This would obviate the need to examine each lung separately and diminish the problem encountered when making measurements on the left lung.

The method may be clinically useful in patients undergoing fibreoptic bronchoscopy for other reasons - for example, if doubt exists about the function of the remaining lung tissue in a patient considered for pulmonary resection. Infection and rejection in lung transplants are often accompanied by a fall in overall spirometric values. ${ }^{16}$ Measurement of unilateral function during diagnostic bronchoscopy could quantify more precisely the effect of such episodes.
The development of hypoxaemia is more likely in patients than in healthy subjects if the occlusion lasts for several minutes. Many lung function tests are based on single breath techniques, however, and bronchial occlusion during these tests carries little or no risk even for those with diseased lungs and pre-existing hypoxaemia.

The technical assistance of Inger Hem, Else-Margrethe Blix, and Christin Hornmoen is greatly appreciated. The study was financially supported by a grant from Glaxo Norway AS

1 Wernly JA, DeMeester TR, Kirchner PT, Myerowitz PD, Oxford DE, Golomb HM. Clinical value of quantitative ventilation-perfusion lung scans in the surgical management of bronchogenic carcinoma. $\mathcal{F}$ Thorac Cardiovasc Surg 1980;80:535-43.

2 Kramer MR, Marshall SE, McDougall IR, Kloneck A, Starnes VA, Lewiston NJ, et al. The distribution of ventilation and perfusion after single-lung transplantation in patients with pulmonary fibrosis and pulmonary hypertension. Transplant Proc 1991;23:1215-16.

3 Neuhaus H, Cherniack NS. A bronchospirometric method of estimating the effect of pneumonectomy on the maximum breathing capacity. $\mathcal{f}$ Thorac Cardiovasc Surg 1968;55:144-8.

4 Quanjer PH, ed. Standardized lung function testing. Clin Respir Physiol 1983;19(Suppl 5):45-51.

5 Horsfield K, Cumming G. Morphology of the bronchial tree in man. 7 Appl Physiol 1968;24:373-83.

6 Jacobaeus HC, Frenckner P, Bjørkman S. Some attempts at determining the volume and function of each lung separately. Acta Med Scand 1932-33;79:174-207.

7 Bjørkman S. Bronchospirometrie, eine klinische Metode die Funktion der mensclichen Lungen getrennt und gleichzeitig zu untersuchen. Acta Med Scand Suppl 1934; 56:24-57.

8 Bezançon F, Braun P, Soulas G, Cachin M. La division des airs. Examen fonctionnel des poumons séparés. Bull Acad Natl Med 1936;115:12-23.

9 Carlens E. A new flexible double-lumen catheter for bronchospirometry. F Thorac Surg 1949;18:742-6.

10 Svanberg $\mathrm{L}$. Influence of posture on the lung volumes, ventilation and circulation in normals. Scand $\mathrm{f}$ Clin Lab Invest Suppl 1957;25:1-195.

11 Ranson-Bitker B, Silbert Aidan D, Le Roy Ladurie $M$. Signification de la répartition de la consommation d'oxygène et de la ventilation avant chirurgie thoracique. Bull Eur Physiopathol Respir 1970;6:687-99.

12 Hughes JMB, Glazier HB, Maloney JE, West JB. Effect of lung volume on the distribution of pulmonary blood flow in man. Respir Physiol 1968;4:58-72.

13 Isawa $T$, Benfield JR, Johnson DE, Taplin GV. Pulmonary perfusion changes after experimental unilateral bronchial occlusion and their clinical significance. Radiology 1971;99:355-60.

14 Thurlbeck WM. Post-mortem lung volumes. Thorax 1979;34:735-9.

15 Pierce RJ, Brown DJ, Denison DM. Radiographic, scintigraphic, and gas-dilution estimates of individual lung and lobar volumes in man. Thorax 1980;35:773-80.

16 Otulana BA, Higenbottam T, Scott J, Clelland C, Ogboaka G, Wallwork J. Lung function associated with histologically diagnosed acute lung rejection and pulmonary infection in heart-lung transplant patients. $\mathrm{Am}$ Rev Respir Dis 1990;142:329-32. 